\begin{tabular}{|c|c|}
\hline Kassel & $\begin{array}{l}\text { Joint Discussion Paper } \\
\text { Series in Economics } \\
\text { by the Universities of } \\
\text { Aachen · Gießen · Göttingen } \\
\text { Kassel - Marburg · Siegen } \\
\text { ISSN 1867-3678 }\end{array}$ \\
\hline
\end{tabular}

No. 25-2009

Bernd Hayo and Matthias Neuenkirch

\title{
Do Federal Reserve Communications Help Predict Federal Funds Target Rate Decisions?
}




\section{Do Federal Reserve Communications Help Predict Federal Funds Target Rate Decisions?}

\section{Bernd Hayo and Matthias Neuenkirch}

Philipps-University Marburg

This version: 11 May 2010

Corresponding author:

Matthias Neuenkirch

Faculty of Business Administration and Economics (FB 02)

Philipps-University Marburg

D-35032 Marburg

Germany

Tel.: $\quad+49(0) 6421-2823090$

Fax: $+49(0) 6421-2823088$

Email: neuenkirch@,wiwi.uni-marburg.de

* Thanks to Kai Carstensen, Ulrich Fritsche, Michael Lamla, Jan-Egbert Sturm, participants of the $10^{\text {th }}$ IWH-CIREQ Macroeconometric Workshop in Halle, the DIW Macroeconometric Workshop 2009 in Berlin, and research seminars in Cardiff and at Université Libre de Bruxelles for their helpful comments on an earlier version of the paper. The usual disclaimer applies. 


\title{
Do Federal Reserve Communications Help Predict Federal Funds Target Rate Decisions?
}

\begin{abstract}
We explain federal funds target rate decisions using macroeconomic variables and Federal Reserve communication indicators. Econometrically, we employ an ordered probit model of a Taylor rule to predict 75 target rate decisions between 1998 and 2006. We find, first, that our communication indicators significantly explain target rate decisions and improve explanatory power in and out of sample. Second, speeches by members of the Board of Governors and regional presidents have a statistically significant and equal-sized effect, whereas the lessfrequent monetary policy reports and congressional hearings are insignificant. Third, our findings are robust to variations in the specification, including changes in the communication strategy. Finally, our communication indicator based on Federal Reserve speeches performs better in explaining target rate decisions than do newswire reports of Fed communications.
\end{abstract}

JEL: $\quad$ E43, E52, E58

Keywords: Central Bank Communication, Federal Reserve Bank, Interest Rate Decision, Monetary Policy, Federal Funds Target Rate, Taylor Rule 


\section{Introduction}

Central bank communication is now widely accepted as an important aspect of monetary policy. Woodford $(2005,55)$ concludes that "the increased willingness of the FOMC under the Chairmanship of Alan Greenspan to speak openly about both current policy decisions and the Committee's view of likely future policy has greatly increased the ability of markets to anticipate Fed policy."

The U.S. Federal Reserve System (Fed) engages in several methods of communication: post-meeting statements accompanying target rate decisions, the semi-annual monetary policy report (mandated by the Humphrey-Hawkins Full Employment Act of 1978), congressional hearings, and speeches by members of the Board of Governors and regional presidents. Usually, all these give a 12-18-month economic outlook for the United States. In recent years, it has become common practice to indicate the future course of U.S. monetary policy, too. The more formalized channels, such as statements and monetary policy reports, are used infrequently ( 8 and 2 events per year, respectively). Other new information of relevance to financial market expectations is conveyed by speeches. Several studies show that U.S. financial market returns and volatility are affected by these less formal types of communication (e.g., Ehrmann and Fratzscher, 2007; Hayo et al., 2008).

In this paper, we focus on the question of whether the Fed's informal communication actually contains useful information about future monetary policy that agents could not have acquired otherwise. Put differently, does Fed communication provide information additional to that already incorporated in a real-time forward-looking Taylor rule? Our prior is that communication - if used properly - can improve forecasts based on a benchmark Taylor rule. While monthly data about output and inflation expectations are adjusted on pre-scheduled dates, communication can be employed more timely, accurately, and can be based on a broader range of indicators.

The remainder of the paper is organized as follows. In the next section, we summarize previous work in this area and outline our contributions to the field. Section 3 describes the construction of our communication indicators and the other variables, as well as the econometric methodology. In Section 4, we investigate whether communication helps explain and predict target rate decisions. Section 5 presents further specifications and robustness checks. Section 6 concludes. 


\section{Related Literature and Our Contribution}

There is an ongoing theoretical debate about the usefulness of central bank communication. The vast majority of researchers highlight the positive effects of communication in terms of enhancing central bank transparency (see, e.g., Woodford, 2005; Sibert, 2006; Gosselin et al., 2007). ${ }^{1}$ Well-executed communication aids private agents in recognizing the central bank's objectives and strategy. Furthermore, it also increases understanding of recent target rate changes and prepares the market for future target rate changes. If an interest rate decision is already expected by market participants, their adjustment costs will be minimized (see, e.g., Woodford, 2001), as they can take the expected interest rate decision into consideration in advance of it taking effect.

The extent to which central bank communication has been successful in practice is an empirical issue (for a broad overview of the literature, see Blinder et al., 2008). Generally, the literature discussing communication as an instrument for explaining target rate decisions employs a Taylor-rule framework. There are only a few studies on the Fed, which we review first. Pakko (2005) finds that post-meeting statements convey useful information for forecasting changes in the federal funds rate target, even after controlling for policy responses to inflation and the output gap. Lapp and Pearce (2000) show that a bias in the statement accompanying Federal Reserve policy decisions significantly affects the probability that the target will be changed in the period between two meetings. Lapp et al. (2003) discover that Fed decisions are not highly predictable using publicly available data, and that adding private information contained in the Greenbook (available after a five-year delay) does not significantly increase predictive accuracy. All three studies underestimate the explanative and predictive power of Fed communication, as they neglect the less formal channel of speeches, which can be used more timely and accurately than post-meeting statements. Thus, we expect our approach to be more successful as it explicitly addresses this problem.

Other papers assess the predictive power of European Central Bank (ECB) communication. Jansen and de Haan (2009) find that communication-based models do not outperform models based on macroeconomic data in predicting decisions. Heinemann and Ullrich (2007) show that a wording indicator measuring the "hawkishness" of the ECB's monthly press conferences can improve the model's fit when added to the standard explanatory variables. However, a model based solely on this indicator performs worse than

\footnotetext{
${ }^{1}$ A noticeable exception is the work by Morris and Shin (2002) and Amato et al. (2002), who argue against frequent central bank communication. They show that a (small) increase in the precision of the information released by a public authority can be welfare-reducing as it decreases the importance of privately formed information. Svensson (2006) reverses this argument: he proves that this outcome emerges only under quite special circumstances as the central bank must have much less precise information than private agents.
} 
the baseline Taylor rule. Gerlach (2007) estimates empirical reaction functions using the ECB's Monthly Bulletin as a guide in choosing variables. Overall, in regard to the ECB, there is no evidence for an improvement of a Taylor rule due to more timely and accurate information possibly spread by communication. Nonetheless, similar to the literature on the Fed, we suspect that these studies underestimate the total effect of communication, as they do not include all types of ECB communication.

In this paper, we explain federal funds target rate decisions using macroeconomic variables and Federal Reserve communication indicators. To our knowledge, which is backed up by Blinder et al.'s (2008) literature review, there are no other studies explaining U.S. target rate decisions using all types of Federal Reserve communication (post-meeting statements, monetary policy reports, congressional hearings, and speeches). The communications are analyzed on the basis of their written contents. Econometrically, we use an ordered probit model to take into account the discrete nature of U.S. target rate decisions. Our sample starts on February 4, 1998 and ends on December 12, 2006, a period that shows an increasing trend in the overall number of communication events. ${ }^{2}$

\section{Data and Econometric Methodology}

In this paper, we present the empirical results of estimating different variations of a Taylor rule (see Section 4), including: (i) a pure Taylor rule using only lagged target rate decisions and macroeconomic variables; (ii) target rate decisions modeled as depending on lagged decisions and communication variables; and (iii) an assessment of a model that includes both macroeconomic and communication variables.

Our analysis takes advantage of a new data set introduced by Hayo et al. (2008), which includes indicator variables for 1,423 speeches and 148 congressional hearings, covering all governors and regional presidents of the Federal Reserve System, as well as 67 post-meeting statements and 20 monetary policy reports. The communications are sorted into three categories depending on whether they indicate likely increases in the federal funds rate, decreases in the rate, or no change in the target rate. Communications that directly reference monetary policy are easily interpreted; others are not so straightforward. For example, speeches presenting a bright economic outlook can be interpreted as an indication of future rate hikes because in good economic times, the Fed needs to take steps to prevent the economy from overheating. Hayo et al. (2008) point out that the Fed typically does not talk

\footnotetext{
${ }^{2}$ In 1998, 114 speeches were delivered by governors and presidents; in 2006 the central bankers spoke 190 times. The starting point of our sample is the first year for which the Federal Reserve Bank and its regional branches systematically began publishing all speeches of by its governors and presidents.
} 
extensively about rate cuts and therefore a speech about a negative economic outlook can be a particularly useful indicator of this possibility. ${ }^{3}$

Consequently, we employ a ternary variable for every communication event. The variable takes the value +1 when the central bank leans toward a rate hike, 0 when the monetary policy will likely remain unchanged, and -1 when loose monetary policy is a strong possibility. ${ }^{4}$ Our sample contains 75 target rate decisions. Often, more than one communication event takes place in the period between Fed meetings. Therefore, we need an indicator that captures the monetary policy stance over the entire inter-meeting period. For this purpose, we net out the instances of tighter and looser monetary policy inclinations and code the communication indicator accordingly. ${ }^{5}$ If the amount of downward and upward news is equal, or if no communication events occur during an inter-meeting period, the variable is coded 0 .

Visual illustrations of the last statement indicator and our communication indicator are shown in Figures 1a and 1b. The former is included to extract the impact of inter-meeting communication from the information available after every target rate decision. Compared with the actual target rate decisions, there is a bias toward target rate hikes in the communication indicator (Figure 1b). This bias is related to the fact that Fed representatives often give a (too) positive economic outlook in times of unchanged monetary policy. Jansen and de Haan (2009) find a similar phenomenon for the ECB. Furthermore, based on our communication indicator, we find that the Fed is very cautious about mentioning rate cuts in too much detail. Only when a rate cut is truly imminent, will the majority of speeches signal such a decision. Except for two outliers in 2001, our communication indicator turns negative, or at least becomes neutral, when the Fed lowers its target rate at the next meeting. The last statement indicator (Figure 1a) is less subject to an overly optimistic economic outlook; it reflects the Fed's interest rate setting very well. One drawback is its availability: the Fed has

\footnotetext{
${ }^{3}$ In a very few cases, a positive economic outlook coincides with a trend toward loose monetary policy, or a pessimistic outlook is accompanied by tighter monetary policy. As the monetary policy stance is a more direct indicator of future target rate decisions, we code these rare cases based on monetary policy stance.

${ }^{4}$ We could also use a scale up to +2 (down to -2 ) when both monetary policy and economic outlook point in the same direction. However, as pointed out earlier, the Fed increased the frequency and the content of its communication gradually during our sample, so a scaling up to +2 could distort the results as earlier speeches often lack a monetary policy part. Furthermore, it is questionable whether an indication via both variables makes a rate change more likely. Finally, preliminary estimations show that the $+1 / 0 /-1$ coding approach is more appropriate.

${ }^{5}$ For example, in our view, eight indications of higher monetary policy do not result in an eight-times-higher probability of a rate hike. Consequently, we use the $+1 / 0 /-1$ scale and ensure the validity of our results with extensive robustness tests. We also controlled for the time distance to the upcoming interest rate decision when creating our communication indicator. Information with regard to the upcoming interest rate decision could be considered more useful the closer the communication takes place to the actual event. However, in our sample, using this additional information slightly decreases the explanatory power of our indicator.
} 
made regular statements only since May $1999 .{ }^{6}$ Therefore, the indicator fails to predict target rate cuts in the autumn of 1998, which are captured by the communication indicator. We expect both indicators to help explain the Fed's interest rate setting behavior, as sometimes the communication indicator reflects information available only after the interest rate decision.

Figure 1a: Federal Funds Target Rate and Last Post-Meeting Statement

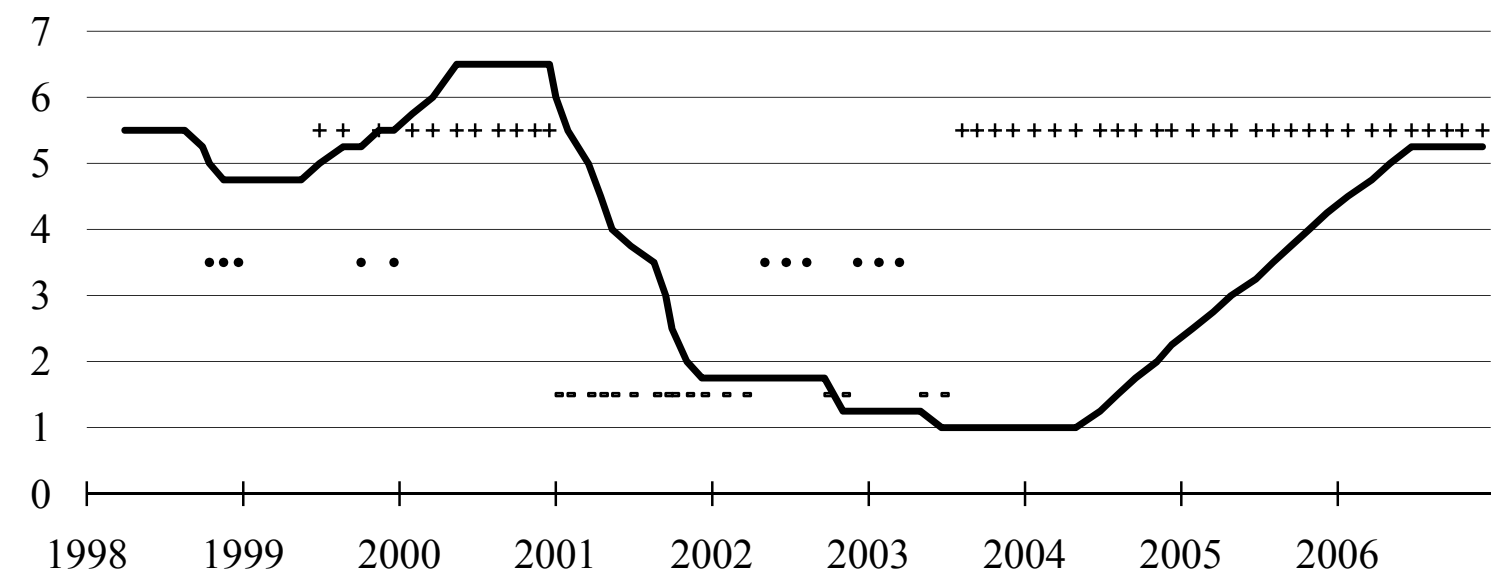

Note: The federal funds target rate is the black line. For the last statement indicator, + means that the indicator suggests rate increase, $\bullet$ that the rate is expected to be constant, and - means that the indicator suggests a rate decrease.

Figure 1b: Federal Funds Target Rate and Communication Indicator

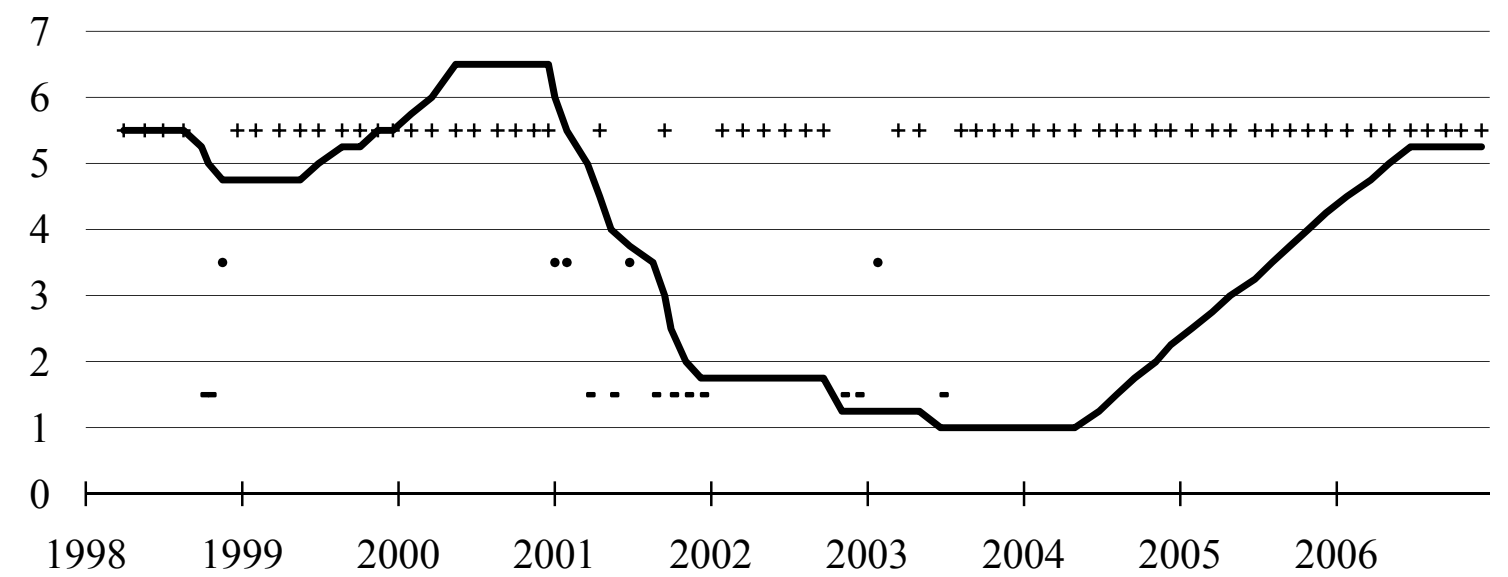

Note: The federal funds target rate is the black line. For the communication indicator, + means that the indicator suggests rate increase, $\bullet$ that the rate is expected to be constant, and - means that the indicator suggests a rate decrease.

Our econometric methodology is a variation of the interest rate setting rule proposed by Taylor (1993). We use real-time data (Orphanides, 2001) available at the time the interest

\footnotetext{
${ }^{6}$ Since May 1999, the Fed makes a regular statement after every interest rate decision. As we are interested in the last statement, this change is effective for the interest rate decision in June 1999. Prior to May 1999, statements were made only after actual rate changes.
} 
rate decisions are made, instead of ex post revised data. ${ }^{7}$ Central banks need to be forwardlooking when planning interest rate decisions, as the maximum monetary policy effect reaches the real economy with a lag of about 12-18 months. Therefore, we employ forward-looking indicators measuring the output gap and inflation (expectations) instead of backward-looking ones based on past economic conditions. A study by Molodtsova et al. (2008) supports our choice; they estimate Taylor rules for the United States and discover that the best fit occurs using real-time output data and inflation forecasts.

We take the perspective of financial agents who want to predict interest rate setting by the Fed. As internal Greenbook data are available only after a five year delay, agents must proxy the Fed's estimates of the relevant macroeconomic variables. Therefore, we utilize the ISM Manufacturing Purchasing Manager Index as a proxy for the forward-looking output gap (Hu and Philipps, 2004). Inflation expectations gathered by the University of Michigan in its Consumer Survey approximate inflation expectations over the next 12 months (Kauppi, 2007). ${ }^{8}$ To ensure stationarity of expected inflation, we compute first differences. The output gap is derived based on the relative deviation of the ISM index from its expansion threshold value at 50 points. $^{9}$

Econometrically, we use an ordered probit model to account for the discrete nature of U.S. target rate decisions (Lapp et al., 2003; Jansen and de Haan, 2009). Our specification is:

(1) Target Rate Decision*

$$
\begin{aligned}
& \left.=\alpha \text { Target Rate Decision }_{t-1}+\beta_{1} \Delta \text { (Inflation Expectations }\right)_{t} \\
& +\beta_{2} \text { ISM Gap }_{t}+\gamma_{1} \text { Last Statement }_{t}+\gamma_{2} \text { Comm. Indicator }_{t}+\varepsilon_{t}
\end{aligned}
$$

where Target Rate Decision ${ }_{t}^{*}$ is the latent continuous variable representing the change in the federal funds target rate. Again, we use a ternary variable $(+1$ represents a rate hike; 0 an unchanged rate; -1 a rate cut) to describe the change in monetary policy. ${ }^{10}$ Target rate

\footnotetext{
${ }^{7}$ The macroeconomic data used in this survey were taken from the St. Louis Fed's Archival Federal Reserve Economic Database.

${ }^{8}$ Preliminary regressions reveal that including the actual level of inflation (see, e.g., Gerlach, 2007) in Equation (1) yields negative and insignificant coefficients for several inflation measures as well as a diminished ability to explain interest rate decisions.

${ }^{9}$ Both the augmented Dickey-Fuller (1979) test and the KPSS test (Kwiatkowski et al., 1992) show that the output gap series and the first difference of the inflation series are stationary. ISM Gap: ADF $-2.09^{* *}$, KPSS 0.105; $\Delta$ (Inflation Expectations): ADF $-10.46^{* * *}$, KPSS 0.096. The ADF test assumes a unit root under the null hypothesis. The KPSS test assumes that the series is stationary under the null hypothesis. $* / * * / * * *$ denotes significance at the $10 / 5 / 1 \%$ level.

${ }_{10}^{10}$ During our sample period, the Fed raised or lowered the target rate 10 times by $50 \mathrm{bps}$, and 29 times by 25 bps. Instead of the ternary variable, we could use a quintuple $(+2 /+1 / 0 /-1 /-2)$ variable to describe Fed behavior. It turns out that the modeling describes very well whether rate hikes/cuts occur or not, but it largely fails to differentiate between small and large interest rate steps. This is also a problem in other studies (e.g., Jansen and de Haan, 2009).
} 
changes occur only when the value of the index function is either below a lower unobserved threshold $\tau_{1}$ or higher than an upper unobserved threshold $\tau_{2}$.

Our Taylor rule incorporates three groups of explanatory variables. First, lagged target rate decisions are included to capture interest rate smoothing behavior. ${ }^{11}$ Second, output gap and expected inflation capture forward-looking macroeconomic information. Third, communication enters the equation via two variables: lagged post-meeting statements ${ }^{12}$ (Lapp and Pearce, 2000; Pakko, 2005) and our communication indicator. The residuals $\varepsilon_{\mathrm{t}}$ are assumed to follow a standard normal distribution, which implies that the probabilities of the different outcomes can be written as:

$\operatorname{Pr}\left[\right.$ Target Rate Decision $\left._{t}=-1 \mid z_{t}\right]=\Phi\left(\tau_{1}-z_{t}^{\prime} \beta\right)$

$\operatorname{Pr}\left[\right.$ Target Rate Decision $\left._{t}=0 \mid z_{t}\right]=\Phi\left(\tau_{2}-z_{t}^{\prime} \beta\right)-\Phi\left(\tau_{1}-z_{t}^{\prime} \beta\right)$

$\operatorname{Pr}\left[\right.$ Target Rate Decision $\left._{t}=1 \mid z_{t}\right]=\Phi\left(\tau_{2}-z_{t}^{\prime} \beta\right)$

where $\Phi$ denotes the cumulative standard normal distribution and $z_{t}$ is our vector of explanatory variables. The ordered probit models are estimated by maximum likelihood (Maddala, 2006) and the threshold variables are obtained simultaneously with the vector of estimated coefficients on the explanatory variables $\beta$.

\section{Explaining Target Rate Decisions with Federal Reserve Communications}

In this section, we present the results of our empirical estimations employing different specifications based on Equation (1). Column (1) of Table 1 shows the model based on macroeconomic news only, ${ }^{13}$ Column (2) incorporates communication variables only, and the Column (3) specification uses both types of information.

Measured by the pseudo $R^{2}$, the joint model (Column (3)) has a slightly better fit than the communication model in Column (2), whereas the macro model (Column (1)) is clearly the worst. Interest rate smoothing is evident in all three specifications, as lagged target rate decisions help predict current ones. The coefficients of inflation expectation and output gap are significant in the Taylor-rule model and they remain significant in the joint model. The same is true of both communication variables (last post-meeting statement and

\footnotetext{
${ }^{11}$ We employ a lagged dependent variable rather than an autoregressive error specification (Rudebusch, 2002) based on results presented by Castelnuovo (2003). Note, however, that the interpretation of interest rate smoothing behavior is still a subject of debate (Rudebusch, 2006).

${ }_{12}$ Post-meeting statements after unscheduled meeting changes are treated like regular post-meeting statements. Thus, agents include these in their information set to predict decisions at the next regular meeting.

${ }^{13}$ We test for endogeneity in our regressions by instrumenting the ISM gap and the change in inflation expectations by their respective lagged values. A Hausman test does not reject the null of exogeneity $\left(\mathrm{Chi}^{2}(2)=\right.$ $0.81)$.
} 
communication indicator), which are also significant in the communication and joint models. ${ }^{14}$ Table 1 also shows that the communication indicator improves the model's ability to correctly explain target rate decisions. Model (2) correctly predicts six more target rate decisions than does the pure Taylor rule of Model (1). The joint model (Model (3)), however, is not an improvement on Model (2) as it mis-predicts one more event than does Model (2).

Table 1: Explaining Target Rate Decisions with Federal Reserve Communication

\begin{tabular}{lccc}
\hline \hline Model & $\mathbf{( 1 )}$ & $\mathbf{( 2 )}$ & $\mathbf{( 3 )}$ \\
\hline Last Rate Decision & $1.82^{* * *}$ & $1.80^{* * *}$ & $2.05^{* * *}$ \\
\hline ISM Gap & $0.07 * * *$ & --- & $0.04 *$ \\
$\Delta$ (Inflation Expectations) & $0.68^{*}$ & --- & $0.77^{*}$ \\
\hline Last Statement & --- & $2.84 * * *$ & $2.88^{* * *}$ \\
Communication Indicator & --- & $1.91 * * *$ & $1.81^{* * *}$ \\
\hline Lower Threshold & $-1.33^{* * *}$ & $-2.21 * * *$ & $-2.47 * * *$ \\
Upper Threshold & $1.88^{* * *}$ & $5.38 * * *$ & $5.94 * * *$ \\
\hline LR Statistic & $61.03 * * *$ & $29.06 * * *$ & $35.91 * * *$ \\
Pseudo Log-Likelihood & -36.72 & -23.50 & -21.30 \\
Pseudo $R^{2}$ & 0.53 & 0.70 & 0.73 \\
\hline Correct Predictions & $59 / 75$ & $65 / 75$ & $64 / 75$
\end{tabular}

Notes: $* * * * * * *$ denote significance at the $10 / 5 / 1 \%$ level. Huber (1967)/White (1980) robust standard errors are used.

Table 2 shows the average marginal effects. ${ }^{15}$ In the Taylor rule specification (Model (1)), the probability of a target rate hike goes up by 27.4 percentage points (pp) after a hike was implemented after the last meeting (instead of an unchanged target rate), while the probability of a rate cut increases by $19.9 \mathrm{pp}$ after a decrease in the variable. If the output gap rises, a rate hike is more likely by 1.2 percentage point, whereas after a corresponding reduction, the probability of a cut goes up by $0.7 \mathrm{pp}$. Finally, higher inflation expectations raise the chance of a rate hike by $11.2 \mathrm{pp}$, while a decline increases the likeliness of a cut by $6.8 \mathrm{pp}$.

When using only communication variables to predict Federal Reserve decisions, the importance of interest rate smoothing decreases (21.4 pp for rate hikes; $7.0 \mathrm{pp}$ for cuts). Some

\footnotetext{
${ }^{14}$ Four unscheduled interest rate changes occurred between meetings during our sample period. Between two meetings, new information about the state of economy or inflation expectations emerges that is not reflected in the last statement or by the macroeconomic variables. Consequently, when controlling for inter-meeting changes, the coefficient of our communication indicator increases slightly, as the Fed can disseminate new information through speeches and prepare the public for a possible change before the next scheduled meeting. Results are available on request.

${ }^{15}$ The following discussion focuses on what happens to the probability of a rate hike if the exogenous variable takes the value of 1 instead of 0 (last rate decision, last statement, and communication indicator) or increases by one percentage point (ISM gap and inflation expectations). Opposite conclusions hold in the case of rate cuts. The probabilities of an unchanged target rate are not discussed due to space constraints.
} 
information in the lagged rate decisions is captured by the combined influence of statements and the communication indicator. ${ }^{16}$ A one-point change in the last statement makes a rate hike more likely by $28.1 \mathrm{pp}$; the corresponding downward shift increases the chance of a rate cut by $10.7 \mathrm{pp}$. The same change in the communication indicator also modifies the probability of target rate changes (22.3 pp for rate hikes; $7.4 \mathrm{pp}$ for cuts).

Table 2: Average Marginal Effects for Models (1)-(3)

\begin{tabular}{llll}
\hline \hline & Prob[Rate Cut] & Prob[No Change] & Prob[Rate Hike] \\
\hline Model (1) Taylor Rule & & & \\
\hline Last Rate Decision & $-0.199 * * *$ & $-0.075 * * *$ & $0.274 * * *$ \\
ISM Gap & $-0.007 * * *$ & $-0.005 * * *$ & $0.012 * * *$ \\
$\Delta$ (Inflation Expectations) & $-0.068 *$ & $-0.044 *$ & $0.112 *$ \\
\hline
\end{tabular}

Model (2) Communication

\begin{tabular}{|c|c|c|c|c|c|}
\hline Last Rate Decision & $-0.070 * * *$ & -0.144 & $* * *$ & 0.214 & $* * *$ \\
\hline Last Statement & $-0.107 * * *$ & -0.173 & $* * *$ & 0.281 & $* * *$ \\
\hline Communication Indicator & $-0.074 * * *$ & -0.150 & $* * *$ & 0.223 & $* * *$ \\
\hline
\end{tabular}

Model (3) Taylor Rule and Communication

\begin{tabular}{llll}
\hline Last Rate Decision & $-0.072 * * *$ & $-0.145 * * *$ & $0.217 * * *$ \\
ISM Gap & $-0.001 *$ & $-0.003 *$ & $0.005 *$ \\
$\Delta$ (Inflation Expectations) & $-0.028 *$ & $-0.065 *$ & $0.092 *$ \\
Last Statement & $-0.098 * * *$ & $-0.168 * * *$ & $0.266 * * *$ \\
Communication Indicator & $-0.064 * * *$ & $-0.134 * * *$ & $0.198 * * *$ \\
\hline \hline
\end{tabular}

Notes: The figures show the average of marginal effects over all observations. $* * * * * * *$ denotes significance at the $10 / 5 / 1 \%$ level.

In the joint model, the average marginal effects of both macro variables become smaller, suggesting collinearity with the communication variables. The latter's average marginal effects remain significant, and similar to the values shown for Model (2). Consequently, the information in Federal Reserve communication partly crowds out publicly available information about the output gap and inflation expectations. The influence of the last post-meeting statement is larger than that of the communication indicator in Models (2) and (3), implying that the Fed follows its interest rate course between two meetings (see Figures $1 \mathrm{a}$ and $1 \mathrm{~b}$ ), whereas the communication indicator provides less new information.

To this point, we have shown the importance of the communication variables for explaining the Fed's target rate decisions. In a next step, we compare the probability of

\footnotetext{
${ }^{16}$ The lesser impact of the lagged interest rate cannot be clearly assigned to either last statements or the communication indicator.
} 
predicting the correct actual decision (hike, no change, or cut) at each Federal Reserve meeting using the pure communication Model (2) and the pure Taylor rule (Model (1)). The differences are plotted in Figure 2.

Figure 2: Gain in Predictability of Target Rate Decisions Due to Consideration of Federal Reserve Communications

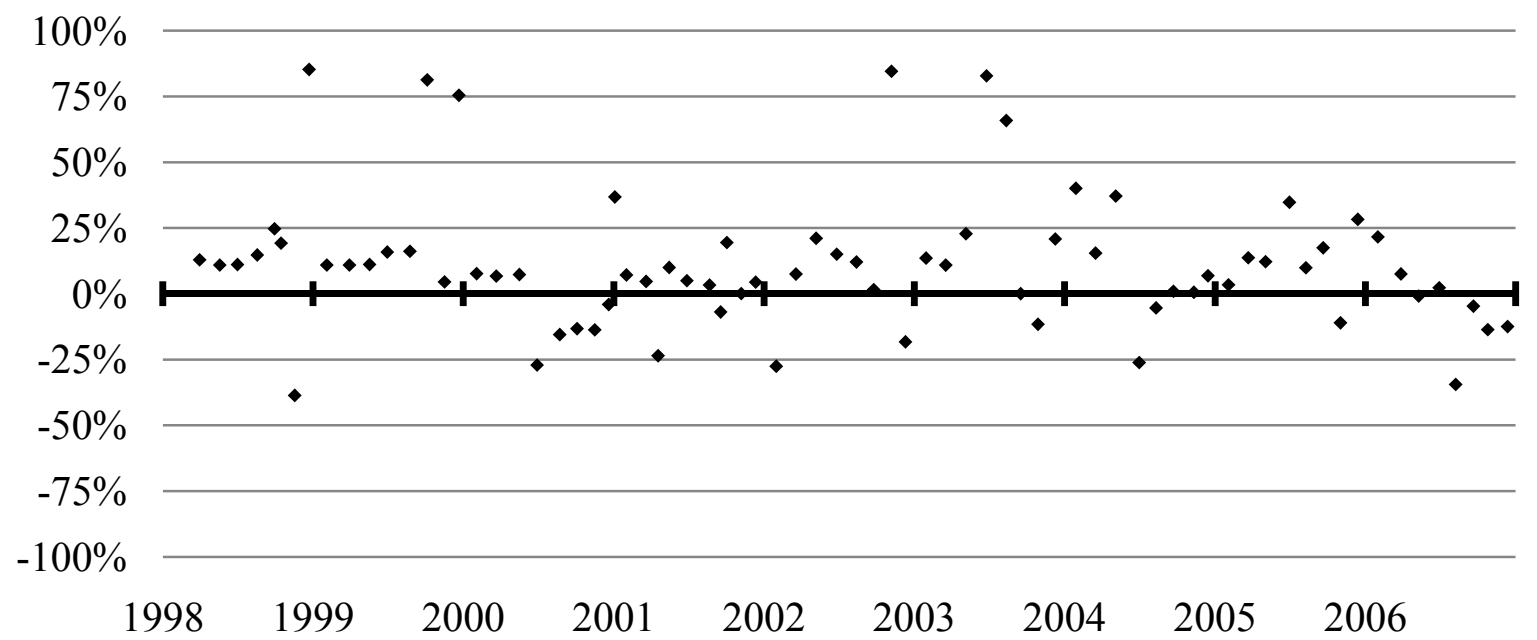

Note: The Y-axis indicates the communication model's (Model (2)) gain (in percentage points) in making the correct prediction compared to the Taylor rule (Model (1)).

There are five decisions where Model (2) gains 75 percentage points or more over Model (1); in six other cases, the increase is at least $25 \mathrm{pp}$. In contrast, there is no case where Model (2) performs more poorly than $50 \mathrm{pp}$, the worst performance being $-38 \mathrm{pp}$. The average gain of the pure communication model over the pure Taylor-rule model is $11 \mathrm{pp}$. Thus, as expected, use of communication indicators, because they are more timely and accurate, substantially improves the probability of making the correct prediction.

Given the absence of necessary data, we cannot study the models' out-of-sample performance. However, to approximate an out-of-sample assessment, we re-estimate Models (1)-(3) initially for the subsample 1998-2002. Then, we predict target rate decisions for the remaining period using recursive out-of-sample forecasts, which requires re-estimating the model after every period. ${ }^{17}$

Table 3 reveals that the predictive ability of the communication-based Model (2) is excellent -30 out of 32 interest rate decisions are correctly anticipated. The two wrong predictions occur at the start and the end of the 2004-2006 tightening cycle (June 30, 2004

\footnotetext{
${ }^{17}$ We start by estimating each model using the first 43 observations and then evaluate whether the model correctly predicts the interest rate decision at $t=44$. Next, we re-estimate the models using the first 44 observations and predict the outcome at $\mathrm{t}=45$, and so on.
} 
and August 8, 2006). The joint Model (3) performs well, too (25 correct predictions), whereas the pure Taylor rule (Model (1)) does more poorly (23 correct predictions).

Table 3: Approximating Out-of-Sample Predictions Using Recursive Estimations

\begin{tabular}{lccc}
\hline \hline & $\mathbf{( 1 )}$ & $\mathbf{( 2 )}$ & $\mathbf{( 3 )}$ \\
\hline Target Rate Cuts & $0 / 1$ & $1 / 1$ & $1 / 1$ \\
No Change in Target Rate & $9 / 14$ & $13 / 14$ & $8 / 14$ \\
Target Rate Hikes & $14 / 17$ & $16 / 17$ & $16 / 17$ \\
\hline All Rate Decisions & $23 / 32$ & $30 / 32$ & $25 / 32$ \\
\hline \hline
\end{tabular}

Notes: The initialization period is 1998-2002 (43 rate decisions) and parameters are updated every period throughout the remaining sample period 2003-2006 (32 rate decisions).

As an alternative to recursive estimations, we can test temporal stability by estimating parameters over the period 1998-2002 and using the resulting models to derive predictions by plugging in values of the relevant variables in each period. Table 4 shows that the communication model (Model (2)) holds up extremely well with regard to stability, whereas Model (1), and Model (3) even more so, suffer from a deterioration of predictive ability.

Table 4: Approximating Out-of-Sample Predictions Using a Fixed Estimation Period

\begin{tabular}{lccc}
\hline \hline & $\mathbf{( 1 )}$ & $\mathbf{( 2 )}$ & $\mathbf{( 3 )}$ \\
\hline Target Rate Cuts & $0 / 1$ & $1 / 1$ & $1 / 1$ \\
No Change in Target Rate & $9 / 14$ & $13 / 14$ & $6 / 14$ \\
Target Rate Hikes & $11 / 17$ & $16 / 17$ & $16 / 17$ \\
\hline All Rate Decisions & $20 / 32$ & $30 / 32$ & $23 / 32$ \\
\hline \hline
\end{tabular}

Notes: The initialization period is 1998-2002 (43 rate decisions) and the out-of-sample period is 2003-2006 (32 rate decisions).

Testing parameter instability using Chow-type tests at a 5\% confidence level (see Figure 3), demonstrates that we can reject constancy in the case of the Taylor rule (Model (1)), but not for the communication model (Model (2)). These results suggest that the communication model is a robust and reliable device for predicting federal funds rate decisions, even out-of-sample. 
Figure 3: Parameter Stability of Models (1) and (2)

(1) Taylor Rule Model

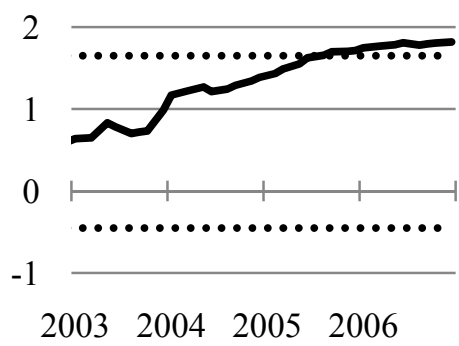

Last Rate Decision

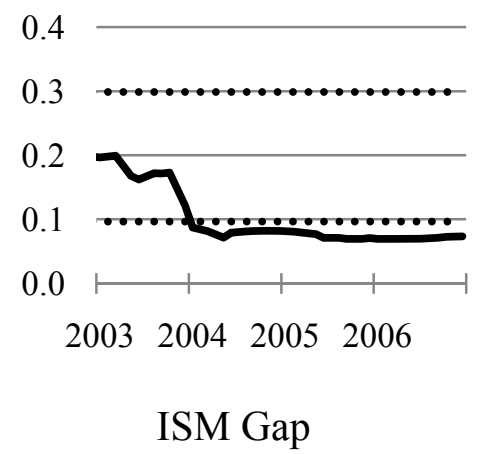

ISM Gap

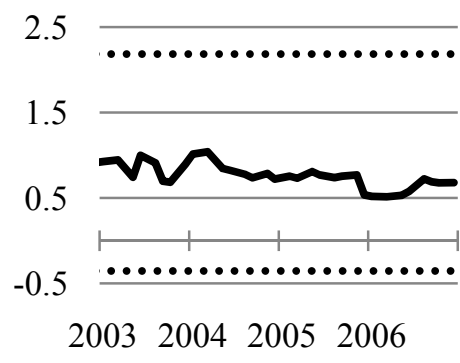

$\Delta($ Inflation Expectations)

(2) Communication Model

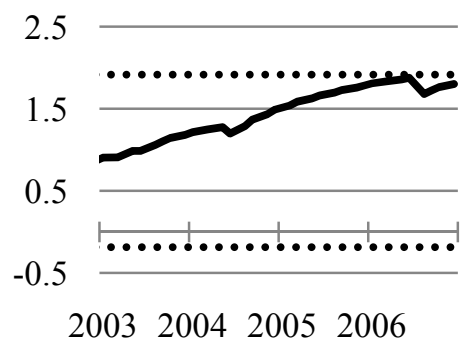

Last Rate Decision

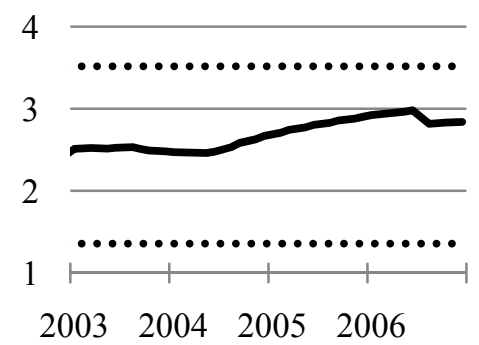

Last Statement

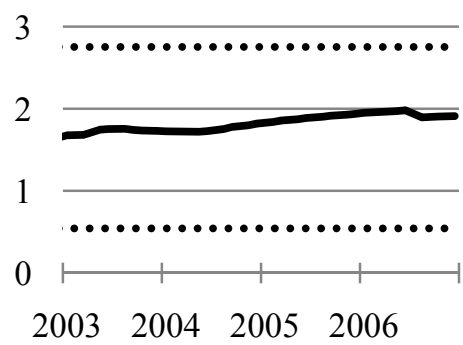

Communication Indicator

Notes: Parameter estimates based on one-step updating over the period 2003-2006 and 95\% confidence bands based on coefficient estimates from the subsample 1998-2002.

\section{Further Results and Robustness Tests}

The outcome of alternative specifications and robustness tests are given in Table 5. Poole (2005) discusses the steps the Fed undertook in an effort to enhance its transparency in postmeeting statements. For example, in August 2003, the Fed replaced the "policy bias/balance of risks" terminology with more forward-looking language. Model (4) of Table 5 explores whether this forward-looking indicator exerts a different impact on the predictability of target rate decisions. We cannot statistically distinguish between either indicator $\left(\mathrm{Chi}^{2}(1)=1.11\right)$, implying that the change in language did not improve the predictive power of Fed communications. ${ }^{18}$

Four unscheduled interest rate changes occurred between meetings during our sample period. Model (5) of Table 5 explores the robustness of our findings with respect to inter-

\footnotetext{
${ }^{18}$ Another effort to increase transparency was implemented in January 2002: henceforward, the names of dissenting members were included in the post-meeting statement. Previously, this information had not been available until the minutes were released following the subsequent Federal Reserve meeting. To control for dissenting votes, we include a variable measuring the lagged dissenter's impact. The prior is that any dissent in the last meeting in either direction should increase the probability of a rate decision in line with the dissenter's vote. Unfortunately, we have collinearity problems, as the model converges only if all communication variables are excluded. However, even in this setup involving fewer explanatory variables, the dissenter's impact is statistically insignificant. Results are available on request.
} 
meeting changes. The latter are modeled as ternary variables, with the value +1 assigned to an unscheduled hike, 0 to a regular decision, and -1 if an inter-meeting cut took place. Although the coefficients for the last statement, the communication indicator, and the inter-meeting moves are large, the marginal effects are comparable to those in the earlier regressions. ${ }^{19}$

Table 5: Further Results in Explaining Target Rate Decisions

\begin{tabular}{|c|c|c|c|c|c|c|}
\hline \multirow[b]{2}{*}{ Last Rate Decision } & \multicolumn{2}{|c|}{ (4) } & \multicolumn{2}{|c|}{ (5) } & \multicolumn{2}{|c|}{ (6) } \\
\hline & 2.26 & $* * *$ & 2.05 & $* * *$ & 2.21 & $* * *$ \\
\hline ISM Gap & 0.06 & $* *$ & 0.04 & & -0.02 & \\
\hline$\Delta$ (Inflation Expectations $)$ & 0.84 & $*$ & 0.80 & $*$ & 0.91 & $*$ \\
\hline Last Statement & --- & & 11.60 & $* * *$ & 2.82 & $* * *$ \\
\hline Last Statement Bias/Balance & 3.27 & $* * *$ & --- & & --- & \\
\hline Last Statement Forward-Looking & 2.50 & $* * *$ & --- & & --- & \\
\hline Communication Indicator & 2.01 & $* *$ & 6.11 & $* * *$ & --- & \\
\hline MPR & --- & & --- & & -0.12 & \\
\hline Testimony & --- & & --- & & 0.29 & \\
\hline Governor's Speech & --- & & --- & & 1.16 & $* *$ \\
\hline President's Speech & --- & & --- & & 1.23 & $* *$ \\
\hline Lagged Inter-Meeting Move & --- & & 11.22 & $* * *$ & --- & \\
\hline Lower Threshold & -2.84 & $* * *$ & -7.16 & $* * *$ & -2.17 & $* *$ \\
\hline Upper Threshold & 6.35 & $* * *$ & 18.93 & $* * *$ & 5.07 & $* * *$ \\
\hline LR Statistic & 30.35 & $* * *$ & 250.06 & $* * *$ & 23.37 & $* * *$ \\
\hline Pseudo Log-Likelihood & -20.56 & & -19.60 & & -21.05 & \\
\hline Pseudo $R^{2}$ & 0.74 & & 0.75 & & 0.73 & \\
\hline Correct Predictions & 64 & $/ 75$ & & & & $/ 75$ \\
\hline
\end{tabular}

Notes: $* * * / * * *$ denote significance at the $10 / 5 / 1 \%$ level. Huber/White robust standard errors are used.

Model (6) of Table 5 examines the impact of different types of Fed communication. Monetary policy reports and congressional hearings have no significant impact, either individually or jointly $\left(\mathrm{Chi}^{2}(2)=0.48\right)$. These types of communication occur too infrequently to contain up-to-date information. ${ }^{20}$ However, speeches are made much more regularly and often contain updates on the business cycle and expected inflation. Consequently, we find that speeches by both groups, governors and regional presidents, significantly help explain interest rate decisions. Statistical testing shows that the coefficients of both groups $\left(\mathrm{Chi}^{2}(1)=0.01\right)$ are indistinguishable. Measured by the number of correct predictions (see last line of Table 5), Model (4) provides no improvement over the more parsimonious Model (2), whereas Models

\footnotetext{
${ }^{19}$ For example, the average marginal effects of the lagged inter-meeting moves are 27.8/10.1 pp for rate hikes/cuts.

${ }^{20}$ We observe only 17 nonzero events for MPRs and 19 for congressional hearings.
} 
(5) and (6) reveal that controlling for inter-meeting moves or further disaggregation of communication leads to slightly better predictability. ${ }^{21}$

Hayo et al. (2008, 27) examine how financial markets react to central bank communication and conclude that "financial market news is not necessarily created at the time when the information becomes available [the time when a speech is actually delivered], but comes into existence only after it goes through a filtering process by the media." To discover whether this media filtering is also present when predicting target rate decisions, we compare our communication indicator with a variable based on news agency reports collected by Ehrmann and Fratzscher (2007). Questions arise as to whether this filtering process helps agents cope with the flood of information and if it is an accurate representation of the Fed's view. Put differently, does the media distort central bank communication to such a degree that observing the original source is more useful?

To answer these questions, we need to shorten our sample period to May 1999-May 2004 (43 observations) so as to match that of Ehrmann and Fratzscher (2007). In line with the procedure sketched above, we derive a communication indicator for the news agency data. Since the newswire information does not include post-meeting statements, we omit these from our set of communication variables to ensure comparability. Table 6 reports the results using the communication indicator created on the basis of our data (Model (7)), the newswire reports (Model (8)), and using both indicators in one equation (Model (9)).

Table 6: Explaining Target Rate Decisions Using Newswire Reports

\begin{tabular}{lrrr}
\hline \hline & $\mathbf{( 7 )}$ & $\mathbf{( 8 )}$ & $\mathbf{( 9 )}$ \\
\hline Last Rate Decision & $1.06^{*}$ & $1.45^{* * *}$ & $1.25^{* *}$ \\
\hline ISM Gap & $0.06^{* * *}$ & 0.04 & 0.03 \\
$\Delta$ (Inflation Expectations) & $0.38^{*}$ & $1.02^{*}$ & 0.56 \\
\hline Comm. Ind. & $0.93^{* *}$ & --- & $0.95 * *$ \\
Comm. Ind. News Agency Reports & --- & 0.68 & 0.68 \\
\hline Lower Threshold & $-0.68^{*}$ & $-1.46^{* * *}$ & $-1.14^{*}$ \\
Upper Threshold & $2.66^{* * *}$ & $1.99 * * *$ & $2.69 * * *$ \\
\hline LR Statistic & $30.88^{* * *}$ & $28.49^{* * *}$ & $24.35^{* * *}$ \\
Pseudo Log-Likelihood & -20.55 & -21.45 & -18.59 \\
Pseudo $R^{2}$ & 0.50 & 0.48 & 0.55 \\
\hline \hline
\end{tabular}

Notes: */**/*** denote significance at the $10 / 5 / 1 \%$ level. Huber/White robust standard errors are used.

\footnotetext{
${ }^{21} \mathrm{We}$ also try to account for possible dispersions in communication. An additional variable is added to Equation (3) that measures the impact of unambiguous communication. We would expect unequivocal communication to have a positive impact on the predictability of target rate decisions. The coefficient is positive, as expected, but statistically insignificant. Results are available on request.
} 
The newswire communication indicator is not significant in either Model (8) or Model (9), whereas our communication variable significantly explains target rate decisions in both Models (7) and (9). We conclude that newswire reports of central bank communications are not a substitute for the original communication when predicting federal funds target rate decisions.

\section{Conclusions}

In this paper, we explain federal funds target rate decisions by means of macroeconomic variables and various forms of Federal Reserve communication. We focus on the question of whether Fed communications contain information additional to that already incorporated in a real-time forward-looking Taylor rule.

The communication variables (lagged statements and our communication indicator) provide a significant and robust explanation of the Fed's target rate decisions. They help correctly predict six additional target rate decisions compared to a Taylor rule and increase the probability of making correct forecasts by an average of 11 percentage points over all target rate decisions. Furthermore, the communication variables help generate quite accurate one-step-ahead forecasts: the outcome of 30 out of 32 Federal Reserve meetings over the period 2003-2006 is correctly predicted. In addition, the coefficients associated with the communication indicators are stable over time, whereas variables in the forward-looking Taylor-rule model are plagued by instability.

Regarding different types of communication, speeches by governors and regional presidents have a statistically significant and equal-sized effect. The infrequency of monetary policy reports and congressional hearings tends to make their impact insignificant. Our findings are robust to a variety of alternative specifications. Changes in Fed transparency do not significantly affect our results. When controlling for inter-meeting target rate changes, our coefficients remain significant. Our communication indicator explains rate decisions much better than does an indicator derived from news agency reports collected by Ehrmann and Fratzscher (2007).

The results of our study suggest that the Fed's communication, particularly in its more informal guise (e.g., speeches by Federal Reserve Governors and Presidents), contains useful information about future monetary policy. Agents cannot acquire this information by relying on a Taylor rule even if this is forward-looking. In other words, the Fed prepares the public for its monetary policy decisions through informal methods of communication and private 
agents' inferences about Fed decisions based on a Taylor rule are not a perfect substitute for this information.

Our inferences are based on data mainly from a period when Alan Greenspan was Chairman of the Federal Reserve Bank. The chairmanship of Ben Bernanke (starting in February 2006) did not cause a noticeable break in the out-of-sample predictions and the parameter stability tests of our communication model (Model (2); see Tables 3 and 4 and Figure 3). However, since these results are based on seven target rate decisions only, it would be interesting to examine the impact of the more recent years of Bernanke's chairmanship. In particular, further studies could address two crucial questions: (1) Do the latest steps taken to increase the Fed's transparency ${ }^{22}$ affect agents' ability to predict target rate decisions? And (2) Does the recent economic and financial crisis have an influence on the importance of central bank communication? Our prior is that central bank communication will be increasingly helpful as the Fed continues the course started during the Greenspan era and continues to increase its openness in communication. Furthermore, the recent economic and financial crisis caused central banks to cut their target rates very quickly. Abrupt changes and, in particular, inter-meeting changes can be prepared for better by timely communication than by monthly economic data.

\footnotetext{
${ }^{22}$ For example, in 2007, the Fed announced that it will make economic projections for longer periods (three years instead of two) and distribute these more often (four times a year instead of two) in an effort to shed light on the likely path of interest rates and optimal levels of inflation.
} 


\section{References}

Amato, J. D., Morris, S., and Shin, H. S. (2002), Communication and Monetary Policy, Oxford Review of Economic Policy 18, 495-503.

Blinder, A., Ehrmann, M., Fratzscher, M., de Haan, J., and Jansen, D.-J. (2008), Central Bank Communication and Monetary Policy: A Survey of Theory and Evidence, Journal of Economic Literature 46, 910-945.

Castelnuovo, E. (2003), Taylor Rules, Omitted Variables, and Interest Rate Smoothing in the US, Economics Letters 81, 55-59.

Dickey, D. A. and Fuller, W. A. (1979), Distribution for Autoregressive Time Series with a Unit Root, Journal of the American Statistical Association 74, 427-431.

Ehrmann, M. and Fratzscher, M. (2007), Communication by Central Bank Committee Members: Different Strategies, Same Effectiveness? Journal of Money, Credit and Banking 39, 509-541.

Gerlach, S. (2007), Interest Rate Setting by the ECB, 1999-2006: Words and Deeds, International Journal of Central Banking 3, 1-46.

Gosselin, P., Lotz, A., and Wyplosz, C. (2007), Interest Rate Signals and Central Bank Transparency, CEPR Discussion Paper 6454.

Hayo, B., Kutan, A., and Neuenkirch, M. (2008), Communicating with Many Tongues: FOMC Speeches and U.S. Financial Market Reaction, MAGKS Joint Discussion Paper Series in Economics 08-2008.

Heinemann, F. and Ullrich, K. (2007), Does it Pay to Watch Central Bankers' Lips? The Information Content of ECB Wording, Swiss Journal of Economics and Statistics 3, 155185.

Hu, L. and Phillips, P. C. B. (2004), Dynamics of the Federal Funds Target Rate: A Nonstationary Discrete Choice Approach, Journal of Applied Econometrics 19, 851-867.

Huber, P. J. (1967), The Behavior of Maximum Likelihood Estimates Under Non-Standard Conditions, Proceedings of the Fifth Berkeley Symposium on Mathematical Statistics and Probability 1, 221-233.

Jansen, D.-J. and de Haan, J. (2009), Has ECB Communication Been Helpful in Predicting Interest Rate Decisions? An Evaluation of the Early Years of the Economic and Monetary Union, Applied Economics 41, 1995-2003.

Kwiatkowski, D., Phillips, P. C. B., Schmidt, P., and Shin, Y. (1992), Testing the Null Hypothesis of Stationarity Against the Alternative of a Unit Root: How Sure Are We that Economic Time Series Have a Unit Root? Journal of Econometrics 54, 159-178.

Lapp, J. S. and Pearce, D. K. (2000), Does a Bias in FOMC Policy Directives Help Predict Intermeeting Policy Changes? Journal of Money, Credit and Banking 32, 435-441. 
Lapp, J. S., Pearce, D. K., and Laksanasut, S. (2003), The Predictability of FOMC Decisions: Evidence from the Volcker and Greenspan Chairmanships, Southern Economic Journal 70, $312-327$.

Maddala, G. S. (2006), Limited-Dependent and Qualitative Variables in Econometrics, Cambridge, Cambridge University Press.

Molodtsova, T., Nikolsko-Rzhevskyy, A., and Papell, D. H. (2008), Taylor Rules and the Euro, MPRA Paper 11348.

Morris, S. and Shin, H. S. (2002), The Social Value of Public Information, American Economic Review 92, 1521-1534.

Orphanides, A. (2001), Monetary Policy Rules Based on Real-Time Data, American Economic Review 91, 964-985.

Pakko, M. R. (2005), On the Information Content of Asymmetric FOMC Policy Statements: Evidence from a Taylor-Rule Perspective, Economic Inquiry 43, 558-569.

Poole, W. (2005), How Predictable Is Fed Policy? Federal Reserve Bank of St. Louis Review $87,659-668$.

Rudebusch, G. D. (2002), Term Structure Evidence on Interest Rate Smoothing and Monetary Policy Inertia, Journal of Monetary Economics 49, 1161-1187.

Rudebusch, G. D. (2006), Monetary Policy Inertia: A Fact or Fiction? International Journal of Central Banking 2, 85-135.

Sibert, A. (2006), Is Central Bank Transparency Desirable? Centre for Economic Policy Research Discussion Paper 5641.

Svensson, L. E. O. (2006), Social Value of Public Information: Comment: Morris and Shin (2002) Is Actually Pro-Transparency, Not Con, American Economic Review 96, 448-452.

Taylor, J. (1993), Discretion Versus Policy Rules in Practice, Carnegie-Rochester Conference Series on Public Policy 39, 195-214.

White, H. (1980), A Heteroskedasticity-Consistent Covariance Matrix Estimator and a Direct Test for Heteroscedasticity, Econometrica 48, 817-830.

Woodford, M. (2001), Monetary Policy in the Information Economy, in: Economic Policy for the Information Economy, Federal Reserve Bank of Kansas City.

Woodford, M. (2005), Central Bank Communication and Policy Effectiveness, NBER Working Paper 11898. 


\section{Appendix}

Table A1: Descriptive Statistics

\begin{tabular}{lccccccc}
\hline \hline & Mean & Max. & Min. & Std. Dev. & $\mathbf{+ 1}$ & $\mathbf{0}$ & $\mathbf{- 1}$ \\
\hline Target Rate Decisions & 0.09 & --- & --- & 0.72 & 23 & 36 & 16 \\
\hline ISM Gap & 4.87 & 32.4 & -20.4 & 11.02 & --- & --- & --- \\
$\Delta$ (Inflation Expectations) & 0.01 & 1.5 & -1.8 & 0.46 & --- & --- & --- \\
\hline Statements & 0.29 & --- & --- & 0.82 & 39 & 19 & 17 \\
Communication Indicator & 0.64 & --- & --- & 0.73 & 59 & 5 & 11 \\
\hline MPR & 0.15 & --- & --- & 0.46 & 14 & 58 & 3 \\
Testimony & 0.15 & --- & --- & 0.49 & 15 & 56 & 4 \\
Governor's Speeches & 0.36 & --- & --- & 0.75 & 39 & 24 & 12 \\
Presidents' Speeches & 0.63 & --- & --- & 0.73 & 58 & 6 & 11 \\
\hline \hline
\end{tabular}

